\title{
TL / ABD Doları Döviz Kuru Belirlenme Modeli: ARDL Sınır Testi Uygulaması
}

\author{
Levent KORAP*
}

ÖZ

Döviz kurlarının uzun dönemli gelişim süreçlerinin tahmin edilmesi hem gelişmiş hem de gelişmekte ekonomilerde uygulanan politikaların etkinlik koşulları açısından belirleyici bir işleve sahip olacaktır. Bu makalede bir döviz kuru belirlenme modeli kapsamında TL / ABD doları 2005Q4-2018Q3 gözlem dönemi için incelenmeye çalışılmaktadır. Kuramsal bir yaklaşım izlenerek parasal model döviz kuru belirlenme mekanizması ortaya konmuş ve ARDL sınır testi eşbütünleşim yöntemi ile tahmin edilmiştir. Bulgular parasal döviz kurunun iktisat kuramının belirttiği temeller ile tutarlı bir şekilde eşbütünleşik bir ilişkiye sahip olduğunu belirtmektedir. Parasal döviz kuru göreceli para arzı ile pozitif bir etkileşim içerisindeyken göreceli reel gelir düzeyindeki bir artış ulusal para biriminin ABD doları karşısında değer kazanması ile sonuçlanmaktadır. Ayrıca, önsel olarak varsayıldığı gibi, parasal döviz kuruyla göreceli faiz oranı arasında negatif ve göreceli beklenen enflasyon oranı arasında pozitif bir ilişki bulunmuştur.

Anahtar Kelimeler: Döviz Kuru, İktisadi Temeller, Modelleme

JEL Sinıflandırması: F31, F41, F47

\section{Exchange Rate Determination Model of TL / US Dollar: ARDL Bounds Testing Application}

\begin{abstract}
Estimating the long run movement of the exchange rates has a determining role for the efficiency of policies in both the developed and the developing economies. In this paper, exchange rate determination mechanism of TL / US dollar is tried to be examined for the 2005Q3-2018Q3 period. By following a theoretical base, the monetary model exchange rate determination mechanism has been constructed, and estimated with ARDL model bounds testing cointegration methodology. The results indicate that nominal exchange rate is cointegrated with the fundamentals suggested by economics theory. There exists a positive relationship between nominal exchange rate and relative money supply and that an increase in the relative income would lead to an appreciation of the domestic currency against the US dollar. Besides, as a priori hypothesized, relative interest variable has a negative relationship and relative inflation differential has a positive relationship with the nominal exchange rate.
\end{abstract}

Keywords: Exchange Rate, Economic Fundamentals, Modelling

JEL Classification: F31, F41, F47

Geliş Tarihi / Received: 28.02.2019 Kabul Tarihi / Accepted: 22.11.2019

\footnotetext{
* Doç. Dr., Kastamonu Üniversitesi, İ̈BF, İktisat Bölümü, ikorap@hotmail.com, ORCID: 0000-0001-6216-5941.
} 


\section{GİRISŞ}

Döviz kuru belirlenme mekanizması ve döviz kurlarına dayalı istikrar politikası uygulamaları çağdaş iktisat yazınında en fazla tartışılan ve özellikle ekonometri düşünce disiplinindeki gelişmeler izlenerek araştırmacılar tarafından üzerinde rahatlıkla uygulama yapılabilmesine olanak sağlayan bir ilgi alanını oluşturmaktadır. Bu tür bir araştırma hem gelişmiş hem de gelişmekte olan ülke ekonomilerinde politika yapıcılara döviz kurunun makro iktisadi büyüme sürecinin önsel beklentiler doğrultusunda tasarlanması ve enflasyon ile mücadelede ekonomide yerleşik fiyat yapışkanlığı olgusunun kırılması amacıyla kullanılması açısından önemli bir bilgi içeriği sağlayabilmektedir. Dolayısıyla döviz kurlarının uzun dönemli gelişim süreçlerinin tahmin edilmesi uygulanan politikaların etkinlik koşulları açısından belirleyici bir işleve sahip olacaktır. Bu doğrultuda gerçekleştirilen iktisadi modellemeler makro iktisat kuramlarının vurguladığı ve döviz kurları arasında geçerli olduğu varsayılan satın alma gücü paritesi ve korunmamış faiz paritesi gibi ya da bunların bir bileşimi şeklindeki çeşitli parite koşullarının değerlendirilmesini olanaklı kılacaktır.

Meese ve Rogoff (1983) öncü çalışması sonrası pek çok diğer çalışma döviz kurlarının davranışının modellenmesinde parasal temellerin etkisi üzerinde durmaktadır. Bu şekilde, bir yandan döviz kurlarının uzun dönemli belirleyici bileşenlerinin diğer yandan kısa dönemli dinamik özelliklerinin saptanmasına çalışılmaktadır. Bu bağlamda olmak üzere, Türkiye ekonomisi gibi gelişmekte olan bir ekonomi için döviz kurlarının belirleyicilerini ortaya koymaya yönelik gerçekleştirilen tahmin içerikli modelleme deneyimleri satın alma gücü paritesi ve korunmamış faiz paritesi ya da açık ekonomi koşullarında bu paritelerin bir bileşimi şeklinde modellenebilecek döviz kurlarının belirlenmesini açıklamaya yönelik uluslararası makro iktisadi kuramların tutarlılığının sınanmasını sağlayacaktır. Bu tür çalışmalar aynı zamanda döviz kurlarına dayalı duruma bağlı istikrar politikalarının beklenen politika hedeflerine ulaşabilmesi konusundaki başarı durumu hakkında da bilgi verecektir. Çağdaş tahmin yöntemlerindeki gelişmeler gerek tek bir ülke para biriminin bir diğer ülke para birimi karşısındaki değerinin belirleyicilerini açıklayan zaman serisi çalışmaları gerekse bu tür bir karşılaştırmanın uluslararası bir düzeyde yapılmasına olanak sağlayan panel veri çalışmaları aracıllı̆̆yla döviz kurlarının belirleyicilerinin saptanmasına yönelik kapsamlı bir bilgi içeriğinin ortaya çıkarmaktadır. 2000 yılı sonrası itibariyle, örneğin, Mark ve Sul (2001), Abhyankar, Sarno \& Valente (2005), Karfakis (2006), Chin, Azali \& Matthews (2007), Shylajan, Sereejesh \& Suresh (2011) ve Afat, Gómez-Puig \& Sosvilla-Rivero (2015) döviz kuru belirlenme modellerinin açıklama gücünü ve birbirlerine karşı üstünlüklerini karşılaştıran çalışmalar durumundadır.

Bu çalışmalar dışında Bahmani-Oskooee ve Kara (2000), Civcir (2004), Özdemir (2004) ve Uz ve Ketenci (2010) gerçekleştirdikleri modellemeler ile bu ilgi alanında Türkiye ekonomisine ait bazı tahmin bulguları üzerinde durmaktadır. Bahmani-Oskooee ve Kara (2000) hata düzeltme modellemesine dayalı olarak döviz kurunda yaşanan dengesizlik karşısında kurun denge değerinin ötesine geçerek sergilediği yüksekten uçuşu (overshooting) kısa ve uzun dönemde sınamaya çalışırken, Civcir (2004) Türk lirasının ABD doları karşısındaki değerini kendi çalışmamıza benzer şekilde döviz kurlarının belirlenmesine yönelik parasal modelden faydalanarak ve eşbütünleşim tahmin yöntemlerine başvurarak incelemekte, kuramsal alt yapıyı destekler bulgular elde etmektedir. Yazar çalışmasında ayrıca 2001 finansal krizi öncesi Türk lirasının aşırı değerlenme eğilimi içerisinde olduğunu göstermektedir. Özdemir (2004) Türk lirası karşısında ABD doları, Alman markı, İngiliz sterlini ve Fransız frangı döviz kurlarını dikkate alarak reel döviz kurlarının durağanlığını satın alma gücü paritesi yaklaşımı temelinde parametrik ve yarı parametrik tahmin yöntemleriyle incelemekte ve döviz kurlarının belirlenmesine yönelik olarak satın alma gücü paritesine destek vermektedir. Benzer şekilde Uz ve Ketenci (2010) döviz kurlarının belirlenmesini yönelik parasal modeli Avrupa Birliğine yeni üye ülkeler ile Türkiye açısından eşbütünleşim tahmin yöntemleri aracıllğıyla sınamakta, ayrıca bu modelin geleceğe yönelik tahmin başarısını rassal yürüyüş modeli ile karşılaştırmaktadır. 
Kendi çalışmamızda döviz kuru belirlenmesine yönelik parasal model Türkiye ekonomisi için TL / ABD doları kullanılarak sınanmaktadır. Bu amaçla gelecek bölümde kuramsal temelli bir parasal döviz kuru belirlenme modeli oluşturulmakta ve iktisat yazını izlenerek bu model enflasyon bekleyişlerini içerecek şekilde kısaca genişletilmektedir. Üçüncü bölümde veri ve zaman serisi özellikleri belirtilmekte, dördüncü bölümde tahmin içerikli yöntemsel bir açıklama yapılmaktadır. Beşinci bölüm çok değişkenli zaman serisi tahmin yöntemlerindeki gelişmeler 1şı̆̆ında Türkiye ekonomisi için ekonometrik bir tahmin denemesine adanmıştır. Altıncı bölümde başlıca sonuçlar özetlenmekte ve çalışma sonlandırılmaktadır.

\section{MODEL OLUŞUMU}

Neely ve Sarno (2002) izlenerek modelleme aşamasına esnek fiyat parasal modeli (FPMM) incelenerek başlanmaktadır. FPMM paranın miktar kuramına dayalı olarak fiyat düzeyi ve döviz kuru değişimlerini para arzı değişiklikleri ile ilişkilendiren varsayımlar doğrultusunda oluşturulmaktadır. McNown ve Wallace (1994) ekonomide istikrarlı bir para talebinin varlığı altında modelin bu özelliğini döviz kurlarının belirlenmesinde satın alma gücü paritesine göre daha fazla bir bilgi içeriğine sahip olması ile ilişkilendirmektedir. Yurt içi ve yurt dışı para piyasaları için aşağıdaki denge koşullarını varsayalım:

$$
\begin{aligned}
& \text { money }_{t}=\text { price }_{t}+\gamma_{1} \text { income }_{t}+\gamma_{2} \text { interest }_{t} \\
& \text { money }_{t}^{f}=\text { price }_{t}^{f}+\gamma_{1}^{f} \text { income }_{t}^{f}+\gamma_{2}^{f} \text { interest }_{t}^{f}
\end{aligned}
$$

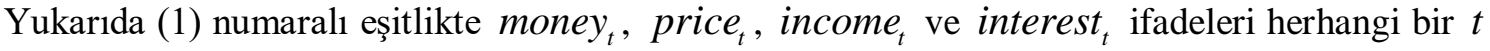
gözlem döneminde sırasıyla yurt içi para arzını, fiyatlar genel düzeyini, reel gelir düzeyini ve faiz oranını simgelemektedir. Faiz oranı dışındaki büyüklükler doğal logaritmik bir yapıda, faiz oranıysa kendi doğrusal yapısında ifade edilmiştir. (2) numaralı eşitlikte ilgili büyüklüklerin yurt dışı değerleri ile oluşturulmuş para piyasası dengesi yer almaktadır. $\gamma_{1}$ ve $\gamma_{2}$ katsayıları para talebinin gelir esnekliğini ve faiz oranı yarı-esnekliğini göstermektedir.FPMM oluşturulurken dikkate alınan ikinci varsayım mutlak satın alma gücü paritesinin geçerliliğidir. Bu durumda iki para birimi cinsinden fiyatlar mal piyasası arbitraj koşullarından kaynaklanan döviz kuru hareketleri aracılığıyla eşitlenme eğilimine girecektir:

$$
\text { er } r_{t}=\text { price }_{t}-\text { price }_{t}^{f}
$$

(3) numaralı eşitlikte $e r_{t}$ ifadesi doğal logaritmik ölçekte yabancı para biriminin ulusal para birimi cinsinden değerini yani nominal döviz kurunu belirtmektedir. (2) numaralı eşitliğin (1) numaralı eşitlikten çıkarılması, $\left(\right.$ price $_{t}-$ price $\left._{t}^{f}\right)$ için çözümlenmesi ve sonucun (3) numaralı eşitliğe sokulması ile döviz kuru belirlenmesine yönelik esnek fiyat parasal modeli elde edilmektedir:

$$
e r_{t}=\left(\text { money }_{t}-\text { mone }_{t}^{f}\right)-\left(\gamma_{1} \text { income }_{t}-\gamma_{1}^{f} \text { income }_{t}^{f}\right)+\left(\gamma_{2} \text { interest }_{t}-\gamma_{2}^{f} \text { interest }_{t}^{f}\right)
$$

Bu noktada çağdaş zaman serisi tahmin yöntemlerinin daha rahat kullanılması için ulusal ve yabancı para piyasalarında para tutumuna yönelik gelir esnekliği ve faiz oranı yarı-esnekliği eşit varsayılarak FPMM eşitliği aşağıda gösterildiği gibi yeniden yazılabilir:

$$
\text { er }_{t}=\left(\text { money }_{t}-\text { money }_{t}^{f}\right)-\gamma_{1}\left(\text { income }_{t}-\text { income }_{t}^{f}\right)+\gamma_{2}\left(\text { interest }_{t}-\text { interest }_{t}^{f}\right)
$$


(5) numaralı eşitlik parasal döviz kuru ile ulusal ve yabancı para arzı farkını yansıtan göreceli para arzı arasında pozitif, ulusal ve yabancı reel gelir düzeyi farkını yansıtan göreceli reel gelir düzeyi arasında negatif bir ilişkiye işaret etmektedir. Ulusal para arzının yurt dışı para arzına göre daha fazla artış göstermesi döviz kurunun değerini arttırırken, ulusal gelir düzeyinin yurt dış1 gelir düzeyine göre daha fazla artış göstermesi döviz kurunun değerini azaltmaktadır.

Göreceli gelir düzeyinin işaretiyle ilgili olarak geleneksel Mundell-Fleming modellemesine göre yurt içi reel gelir düzeyindeki, dolayısıyla ekonominin dış alım miktarındaki bir artı̧̧ sonucu ticaret dengesinin yeniden sağlanabilmesi için ulusal para biriminin yabancı para birimi karşısında değer kaybetmesi gerekmektedir. Bu şekilde parasal döviz kuru ve göreceli gelir düzeyi arasında negatif bir ilişki meydana gelecektir. Oysaki FPMM yaklaşımına göre yurt içi reel gelir düzeyindeki bir artış denge koşulları altında para piyasasında bir talep fazlasına yol açmakta, iktisadi birimler bu duruma harcama düzeylerini azaltarak uyum sağlamaktadır. Bunun sonucunda yurt içi fiyat düzeyinde gerçekleşen azalma ulusal para biriminin satın alma gücü paritesi doğrultusunda değerlenmesine neden olmaktadır.

Yukarıdaki modellemenin ışığında FPMM yaklaşımı ile ekonomideki fiyat katılıklarının varlığını vurgulayan Keynesgil yaklaşımın katı fiyat parasal modeli (SPMM) arasındaki ayırımı dikkate alalım. Politika yapıcıların sınırlayıcı bir para politikası uygulamaya karar verdiklerini ve ekonomide yerleşik fiyat katılıkları sonucu reel para arzının daraldığı varsayılsın. Bu daralma para piyasası dengesinin yeniden sağlanması için faiz oranlarının yükselmesini gerektirecek, göreceli faiz oranındaki yükselme sermaye girişlerini arttırarak ulusal paranın yabancı para birimleri karşısında değerlenmesi ile sonuçlanacak, parasal döviz kuru denge döviz kurundaki azalmadan daha büyük ölçüde düşecektir. Sonuç olarak parasal döviz kuru ile göreceli faiz oranı arasında negatif bir ilişki ortaya çıkacaktır.

Neely ve Sarno (2002) beklenen döviz kuru değer kaybının göreceli faiz oranına eşit olması durumunda, yani korunmamış faiz paritesi varsayımı altında kısa dönem dengesine ulaşılacağını, bununla beraber fiyat değişimlerine izin verilen uzun dönemde yurt içi fiyatların para arzındaki azalmaya bağlı olarak düşüş göstereceğini ve reel para arzının yeniden artmaya başlayarak yurt içi faiz oranlarını düşüreceğini belirtmektedir. Bunun sonucunda döviz kuru uzun dönem satın alma gücü paritesine doğru yavaşça değer kaybedecektir. Bu açıklamalar doğrultusunda SPMM döviz kuru belirlenme ilişkisini aşağıdaki gibi yazabiliriz:

$$
\begin{aligned}
& \text { er }_{t}=\left(\text { money }_{t}-\text { money }_{t}^{f}\right)-\gamma_{1}\left(\text { income }_{t}-\text { income }_{t}^{f}\right)-(1 / \theta)\left(\text { interest }_{t}-\text { interest }_{t}^{f}\right) \\
& +\left[\gamma_{2}+(1 / \theta)\right]\left(\text { inflation }_{t}-\text { inflation }_{t}^{f}\right)
\end{aligned}
$$

Eşitlik (6)'da inflation ${ }_{t}$ ve inflation $_{t}^{f}$ sırasıyla yurt içi ve yurt dışı enflasyonu göstermektedir. Eşitlik (6) ve eşitlik (5) arasındaki fark birincisinin mal piyasası fiyatlarının $\theta$ oranında yavaş uyumunu ve ikincisinin satın alma gücü paritesi doğrultusunda esnek fiyatları varsaymasıdır.

\section{VERİ VE ZAMAN SERİSI ÖZELLIKLERİ}

Çalışmamızda eşitlik (6) ile belirtilen nihai SPMM döviz kuru belirlenme modelinin Türkiye ekonomisi için tahmin edilmesi amaçlanmaktadır. Üçer aylık gözlem aralığını kullanan örneklem dönemi 2005Q4 - 2018Q3 olarak belirlenmiştir. Başlangıç döneminin 2005Q4 olarak belirlenmesinin nedeni bu tarihten itibaren Türkiye Cumhuriyet Merkez Bankası (TCMB) tarafından Türkiye ekonomisinde para arzı tanımlarında değişikliğe gidilerek bu tanımların bankacılık sistemindeki yerli para cinsinden mevduatlar ile yabancı para birimi cinsinden mevduatların yerli para birimi cinsinden değerinin toplamı şeklinde hesaplanmasıdır. Parasal 
döviz kuru değişkeni $\left(e r_{t}\right)$ için Türk lirası (TL) / ABD doları dikkate alınmıştır. Çalışmada parasal büyüklük olarak Türkiye ekonomi ve ABD ekonomisi için geniş kapsamlı para arz göstergeleri kullanılmış, bu büyüklük dolaşımdaki para miktarı, bankacılık sistemindeki vadesiz mevduatlar, bankacılık sistemindeki vadeli mevduatlar, yeniden satınalma (REPO) sözleşmeleri, para piyasası fonları ve ihraç edilen menkul değerler toplamı şeklindeki M3 para arzıyla $\left(\right.$ money $\left._{t}\right)$ temsil edilmiştir. Parasal büyüklük için 2010: 100 temel y1lını dikkate alan bir endeks kullanılmıştır. Reel gelir büyüklüğü $\left(\right.$ income $\left._{t}\right)$ için zincirleme hacim endeks yöntemine göre hesaplanan gayrisafi yurt içi hasıla (GSYIH) verileri kullanılmış, bu amaçla Türkiye ekonomisi için 2009 ve ABD ekonomisi için 2012 temel yılı dikkate alınmıştır. Faiz oranı değişkeni (interest $t_{t}$ ) için Türkiye ekonomisinden Hazine Müsteşarlığı aylık iç borçlanma ortalama bileşik faizi dönem ortalaması ve ABD ekonomisinden üç aylık Hazine bonosu faiz oranı verileri kullanılmıştır. Enflasyon oranı değişkeni (inflation $\left.{ }_{t}\right) 2015$ temel yılına dayalı üçer aylık tüketici fiyat endeksi değişim oranlarına dayanmaktadır. Türkiye ekonomisine ait faiz oranları dışındaki veriler Ekonomik İşbirliği ve Kalkınma Teşkilatı (OECD) elektronik veri dağıtım sisteminden (https://stats.oecd.org/, erişim tarihi: 06.12.2018) ve Türkiye ekonomisine ait faiz oranları da T.C. Cumhurbașkanlığı Strateji ve Bütçe Başkanlığı elektronik veri dağıtım sisteminden (https://www.sbb.gov.tr/, erişim tarihi: 06.12.2018) derlenmiştir. Parasal döviz kuru, göreceli para arzı ve göreceli reel gelir düzeyi için doğal logaritma işlemcisi kullanılmış, göreceli faiz oranı ve göreceli enflasyon oranı için için bu değerler oran şeklindeki bir büyüklük oldukları için böyle bir dönüşüm gerçekleştirilmemiştir. Çalışmada model tahminine geçilmeden önce kullanılan değişkenlerin birim kök bilgisi aşağıda incelenmeye çalışılmıştır. Bu amaçla Lee ve Strazicich (2003) tarafından önerilen ve sınama sürecinde içsel kırılmaların varlığına izin veren çağdaş bir birim kök sınama yöntemine başvurulmuştur. Kırılma altında birim kökün varlığı $H_{0}$ varsayımına dayalı sınama sonuçları Tablo 1 içerisinde okuyucuya aktarılmaktadır:

Tablo 1: Lee-Strazicich (2003) Birim Kök Sınaması: İki İçsel Kırılma

\begin{tabular}{|c|c|c|c|}
\hline Değișkenler & Model: Crash & Model: Break & Çıkarsama \\
\hline$e r_{t}$ & -2.42 & -5.27 & $I(1)$ \\
\hline$\Delta e r_{t}$ & -5.76 & -6.48 & $I(0)$ \\
\hline money $_{m 3, t}$ & -1.80 & -6.31 & $I(0)$ veya $I(1)$ \\
\hline$\Delta_{\text {money }}{ }_{m, t}$ & -5.64 & -6.86 & $I(0)$ \\
\hline income $_{t}$ & -2.39 & -5.69 & $I(1)$ \\
\hline sincome $_{t}$ & -3.65 & -8.38 & $I(0)$ \\
\hline interest $_{t}$ & -6.83 & -4.70 & $I(0)$ veya $I(1)$ \\
\hline$\Delta$ interest $_{t}$ & -7.76 & -9.67 & $I(0)$ \\
\hline inflation $_{t}$ & -3.36 & -6.93 & $I(0)$ veya $I(1)$ \\
\hline$\Delta_{\text {inflation }_{t}}$ & -4.79 & -9.01 & $I(0)$ \\
\hline Kritik değ. $5 \%$ & -3.56 & -6.18 & \\
\hline
\end{tabular}


Yukarıda $\Delta$ fark işlemcisidir. Tablo iki olası çoklu kırılma altında Lee-Strazicich (2003) en küçük sınama istatistiklerini (tau) sunmaktadır. Tahmin bulguları, seçilen örneklem içerisindeki bilinmeyen bir tarihte yapısal kırılmayı dikkate almaktadır. Sınamalar için dikkate alınan en yüksek gecikme uzunluğu 5 olarak saptanmış ve Schwarz bilgi ölçütü dikkate alınmıştır. Birim kök tahmin bulgularına göre parasal döviz kuru ve göreceli gelir düzeyi değişkenleri birinci dereceden bütünleşik bir yapıya sahipken göreceli para arzının, göreceli faiz oranının ve göreceli enflasyon oranının kullanılan birim kök modeline göre düzey değerleri açısından $I(0)$ ya da $I(1)$ olma durumu çelişkili bir sonuç üretmektedir. Bu bulgular doğrultusunda eşitlik (6) ile belirtilen modelin tahmin işlemi için çağdaş bir zaman serisi tahmin yöntemi olan ardışık bağlanımlı gecikmesi dağıtılıış sınır testi yaklaşımına başvurulacaktır.

\section{ARDIŞIK BAĞLANIMLI GECIKMESİ DAĞITILMIŞ ARDL SINIR TESTİ}

Kullanılan değişkenlerin farklı bütünleşme derecesine sahip olması nedeniyle tek denklemli Engle ve Granger (1987) yöntemi ya da bir vektör ardışık bağlanım (VAR) yapısı altında en çok olabilirlik temelli Johansen (1995) çok değişkenli eşbütünleşim yöntemi dikkate aldığımız veri yapısına uygun düşmemektedir. Pesaran ve devamı (2001) tarafından önerilen $A R D L$ sınır testi $I(0)$ ya da $I(1)$ değişkenlerin bir eşbütünleşik değişken uzayında bulunmalarına izin vermektedir. Aşağıdaki vektör hata düzeltme modelini ele alalım:

$$
\Delta Y_{t}=\mu+\lambda Y_{t-1}+\sum_{j=1}^{p-1} \gamma_{j} \Delta Y_{t-j}+\varepsilon_{t}
$$

Yukarıda $Y_{t}=\left[y_{t} x_{t}\right]^{\prime}$ şeklinde tanımlanan değişken vektörüdür. $\mu=\left[\mu_{y} \mu_{x}\right]^{\prime}$ sabit katsayı vektörü ve $\Delta=(1-L)$ fark işlemcisini göstermektedir. $\varepsilon_{t}=\left[\varepsilon_{y} \varepsilon_{x}\right]^{\prime} \sim N(0, \Omega)$ hata terimleri vektörünün normal dağılımlı, sıfır ortalamalı ve sabit varyanslı olduğu varsayılmaktadır. $\lambda$ uzun dönem çarpan matrisi ve $\gamma$ kısa dönem tepki matrisidir:

$$
\begin{aligned}
& \lambda=\left[\begin{array}{l}
\lambda_{y y} \lambda_{y x} \\
\lambda_{x y} \lambda_{x x}
\end{array}\right]=-\left(I-\sum_{j=1}^{p} \phi_{j}\right) \\
& \gamma_{j}=\left[\begin{array}{l}
\gamma_{y y, j} \gamma_{y x, j} \\
\gamma_{x y, j} \gamma_{x x, j}
\end{array}\right]=-\sum_{k=j+1}^{p} \phi_{k}
\end{aligned}
$$

$I$ birim matrisi ve $\phi_{j}$ vektör ardışık bağlanım katsayı matrisidir. $\lambda$ matrisinin köşegen elemanlarının sınırlandırılmaması zaman serilerinin $I(0)$ ya da $I(1)$ olmasına olanak sağlamaktadır. Örneğin $\lambda_{y y}=0$ ifadesi $y$ değişkeninin $I(1)$ ve $\lambda_{y y}<0$ ifadesi değişkenin $I(0)$ olmasını ifade etmektedir. Uzun dönem çarpan matrisinin köşegen dışı elemanlarından biri, $\lambda_{y x}$ ya da $\lambda_{x y}$, sıfır değerini alabilmektedir. Bu yaklaşım ile tek denklemli eşbütünleşik bir ilişki değişkenlerin $I(0)$ ya da $I(1)$ olmalarına aldırış edilmeksizin tahmin edilebilmektedir:

$$
\Delta y_{t}=\alpha+\varphi y_{t-1}+\delta x_{t-1}+\omega \Delta x_{t}+\sum_{j=1}^{p-1} \beta_{p, j} \Delta y_{t-j}+\sum_{j=1}^{q-1} \beta_{x, j} \Delta x_{t-j}+u_{t}
$$

(10) no'lu eşitlikte $\varphi$ ve $\delta$ uzun dönem çarpan katsayılarını ve $\Delta y_{t-j}$ ve $\Delta x_{t-j}$ hata düzeltme modelinin kısa dönem dinamik yapısını göstermektedir. Sınır testi yaklaşımı (10) no’lu 
eşitliğin trend bileşenini içeren veya içermeyen bir şekilde en küçük kareler $(O L S)$ yöntemiyle tahmin edilmesini gerektirmekte ve aşağıdaki varsayımlar doğrultusunda $F$ - istatistikleri yardımıyla $y_{t}$ ve $x_{t}$ değişkenlerinin düzey değerleri arasında uzun dönemli bir ilişkiyi göstermektedir:

$$
\begin{aligned}
& H_{0}: \varphi=0, \delta=0 \\
& H_{1}: \varphi \neq 0, \delta \neq 0
\end{aligned}
$$

(11) no'lu eşitlikte $F$ - ya da Wald - sınamaları ile $H_{0}$ hipotezinin reddedilmesi $H_{1}$ hipotezinin kabul edilmesine yol açacak ve değişkenler arasındaki uzun dönemli bir denge ilişkisini gösterecektir. Tahmin edilen istatistikler Pesaran ve devamı (2001) çalışmasında aktarılan ve standart olmayan bir dağılıma sahip ölçüt değerlerin kavuşmazda sahip olması gereken değerlerle karşılaştırılmaktadır. Hesaplanan $F$ - istatistiğinin kritik değerleri ifade eden sınırların dışına düşmesi durumunda, değişkenlerin $I(0)$ ya da $I(1)$ şeklinde bütünleşme derecelerini bilmeye gerek kalmaksızın düzey değerleri arasında eşbütünleşik bir ilişkinin varlı̆g1 saptanabilmektedir. $F-$ istatistiğinin üst kritik değerinin üzerinde tahmin edilmesi değişkenler arasında eşbütünleşik bir ilişkinin bulunmadığı $H_{0}$ varsayımının reddedilmesine yol açmakta, $F-$ istatistiğinin alt kritik değerinden düşük bulunmasıysa $H_{1}$ varsayımının kabul edildiğini ve bu doğrultuda değişkenler arasındaki olası eşbütünleşik bir ilişki durumunun bulunmadığını göstermektedir. Hesaplanan $F$ - istatistiğinin dikkate alınan kritik değerlerin arasına düşmesi durumundaysa, değişkenler arasındaki olası bir eşbütünleşik ilişkinin varlığıyla ilgili olarak değişkenlerin bütünleşme derecelerinin bilinmesi gerekmektedir. $\mathrm{Bu}$ tahmin sürecinin yanı sıra (10) no'lu eşitlikte bağımlı değişkenin bir dönem gecikmeli katsayısının $t$ istatistiği değerinin Pesaran ve devamı (2001) tarafindan aktarılan kritik değerleri aşması da modeldeki değişkenler arasında eşbütünleşik bir ilişkinin varlığını gösterebilecektir. ARDL temelli sınır testi küçük örneklemlerde dahi tutarlı uzun dönem katsayı tahmincileri üretebilmektedir.

\section{SINIR TESTI TAHMIN BULGULARI}

Bir sonraki aşamada sonuçların tutarlılığını sınayabilmek için Pesaran ve devamı (2001) tarafindan önerilen $A R D L$ eşbütünleşim denklemi ve hata düzeltme modeli tahmin edilmiştir. $A R D L$ modelinde dikkate alınan bağımlı değişken ve açıklayıcı değişkenler için gecikme sayısı en çok 4 olarak dikkate alınmak üzere Akaike bilgi ölçütü $(A I C)$ kullanılarak pek çok $A R D L$ modeli bulunmuştur. Değerlendirme amaçlı tahmin edilen model sayısı 2500'dür. Bu modeller açısından herhangi bir deterministik bileşenin dikkate alınmaması ya da deterministik bileşen olarak yalnız sabit katsayının dikkate alınması durumunda $\operatorname{ARDL}(3,1,3,0,0)$ modeli ve deterministik bileşen olarak sabit katsayı ve trendin birlikte dikkate alınması durumunda $\operatorname{ARDL}(1,1,3,0,0)$ modeli bilgi ölçütünü en küçük yapan uygun model olarak saptanmıştır. Eşbütünleşik yani durağan yapıdaki iktisadi bir ilişkinin varlığı dikkate alınan deterministik bileşen varsayımlarına bağlı olarak Tablo 2 içerisinde sunulmaktadır. İstatistiksel olasılık değerleri [ ] içerisindedir. Uzun dönem düzey değer eşitliklerinin incelenmesi trend bileşenini içeren modellerin en düşük $F$-Sinır testi $F$-istatistiğine sahip olduğunu göstermektedir. Ayrıca trend bileşeninin koşullu hata düzeltme modelinde yer almasına karşılık uzun dönem 
düzey değer eşitliğine kısıtlanmadığı modelde $t$-Sınır testi $t$-istatistiği de mutlak değer olarak kritik değerlerinin altında bir sonuç vermektedir. Dolayısıyla tahmin edilen döviz kuru belirlenme denkleminde trend bileşenine yer verilmeyecektir. Bütün modeller içerisinde deterministik bileşenler açısından yalnız sabit terimin koşullu hata düzeltme modelinde yer aldığı ve uzun dönem düzey değer eşitliğine kısıtlanmadığı 'kısıtlanmamış sabit \& trend yok' modeli en yüksek $F$-istatistiğine sahip model olarak bulunmaktadır. İzleyen bölümde bu model ile çözümlemeye devam edilecektir. Tahmin edilen eşitlik (12) aşağıya aktarılmıştır:

Tablo 2: Uzun Dönem Düzey Değerler Eşitliği ve Sınır Testi

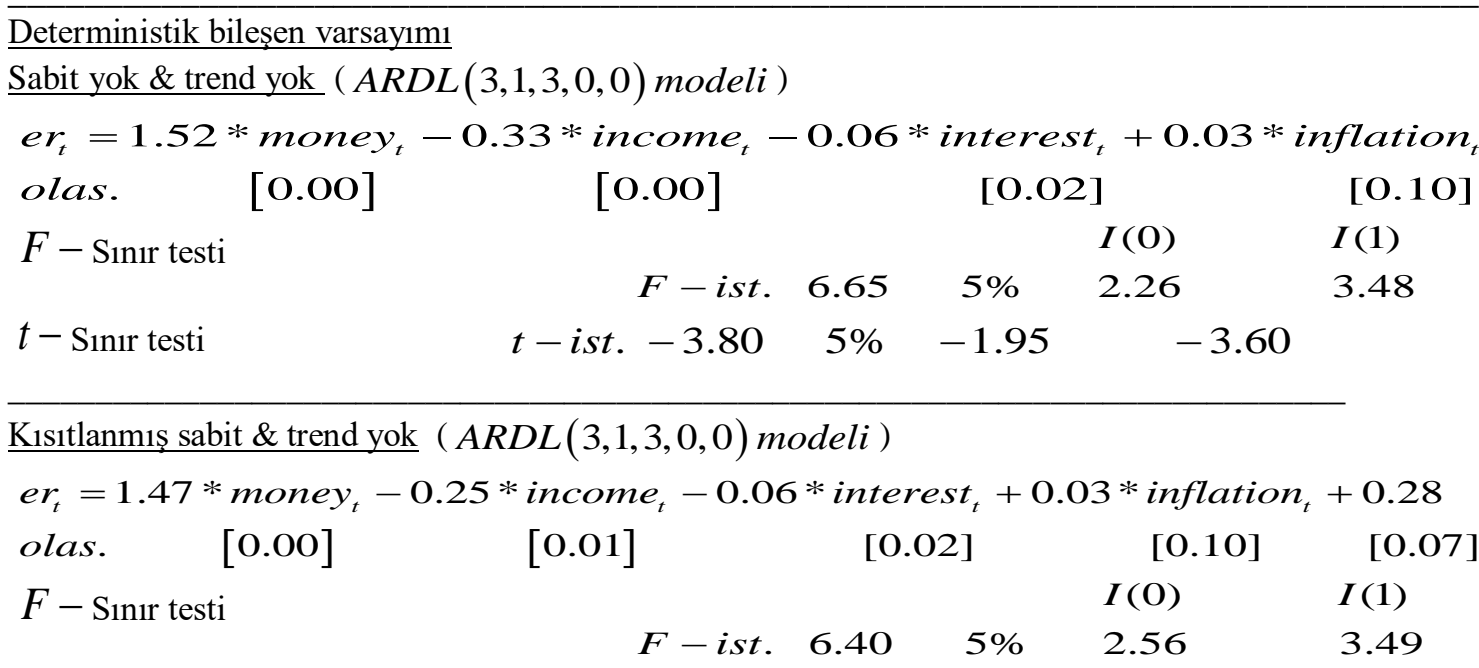

Kisitlanmamıș sabit \& trend yok $(A R D L(3,1,3,0,0)$ modeli $)$

er $r_{t}=1.47 *$ money $_{t}-0.25 *$ income $_{t}-0.06 *$ interest $_{t}+0.03 *$ inflation $_{t}$

olas. [0.00] [0.01] [0.02] [0.10]

$F-$ Sinır testi

$$
\text { F-ist. } \quad 6.76 \quad 5 \% \quad 2.86
$$

$t-$ Sinır testi

$$
t \text {-ist. }-4.90 \quad 5 \% \quad-2.86 \quad-3.99
$$

Kısıtlanmamıș sabit \& kısıtlanmış trend ( ARDL $(1,1,3,0,0)$ modeli $)$

er $r_{t}=1.06 *$ money $_{t}-0.20 *$ income $_{t}-0.05 *$ interest $_{t}+0.14 *$ inflation $_{t}-0.28 *$ trend

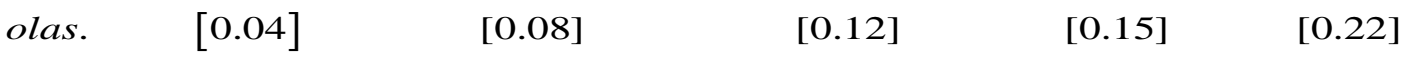

$F-$ Sinır testi

$I(\mathrm{O})$

$$
\begin{array}{lllll}
\text { F-ist. } & 5.52 \quad 5 \% & 3.05 & 3.97
\end{array}
$$

$\underline{\text { Kısıtlanmamıs sabit \& kısıtlanmamıs trend }}(\operatorname{ARDL}(1,1,3,0,0)$ modeli $)$

$$
\begin{aligned}
& \text { er } r_{t}=1.06 * \text { money }_{t}-0.20 * \text { income }_{t}-0.05 * \text { interest }_{t}+0.14 * \text { inflation }_{t} \\
& \text { olas. [0.04] [0.08] [0.12] [0.15] } \\
& F-\text { Sinır testi } \\
& \text { F-ist. } 4.75 \quad 5 \% \quad 3.47 \\
& \begin{array}{llllll}
t-\text { Sinır testi } & t-i s t . & -0.75 & 5 \% & -3.41 & -4.36
\end{array}
\end{aligned}
$$




$$
\begin{aligned}
& e r_{t}=1.47 * \text { money }_{t}-0.25 * \text { income }_{t}-0.06 * \text { interest }_{t}+0.03 * \text { inflation }_{t} \\
& \text { olas. }[0.00] \quad[0.01] \quad[0.02] \quad[0.10]
\end{aligned}
$$

Eşitlik (12) içerisinde aktardığımız bulgular eşitlik (6)'da belirtilen SPMM döviz kuru belirlenme mekanizmasına destek verir bir yapıdadır. Parasal döviz kuru ile göreceli para arzı pozitif ve göreceli reel gelir düzeyi negatif, aynı zamanda istatistiksel olarak anlamlı bir ilişkiye sahiptir. Dolayısıyla, Karfakis (2006) izlenerek uzun dönemde pozitif bir parasal şokun döviz kuru düzey değerini kalıcı bir şekilde yükselteceği ve göreceli reel gelir düzeyindeki bir artışın da ulusal paranın ABD doları karşısında değerlenmesine yol açacağı söylenebilecektir. Karfakis bu tür bir sonucu ekonomik büyümeyi arttıran politika seçeneklerinin güçlü bir ulusal para meydana getirmesine atfetmektedir. Aynı zamanda, istatistiksel olarak anlamlı bir şekilde ve önsel beklentilerimiz doğrultusunda, göreceli faiz oranı değişkeni negatif ve göreceli enflasyon oranı değişkeni pozitif anlamlı bir işarete sahiptir.

Uzun dönem durağan denge koşulları altında pozitif bir göreceli enflasyon farklılığ1 beklendiği gibi ulusal paranın ABD doları karşısında değer kaybetmesine neden olacaktır. Farklı deterministik bileşen varsayımlarının dikkate alınması durumunda istatistiksel anlamlılık düzeyi farklılık gösterebilmekle birlikte katsayı büyüklüğü ve işareti açısından benzer bulgular elde edilmesi örneklem döneminde tahmin sonuçlarının güvenilirliğini arttırıcı bir nitelik taşımaktadır. Model bulguları genel olarak değerlendirildiğinde kullandığımız veriler kapsamında SPMM döviz kuru belirlenme modeline güçlü bir destek verildiği görülmektedir. Model tanı koyma sinama bilgileri Tablo 3'te verilmektedir:

Tablo 3: Tanı Koyma (Diagnostic) Bilgileri

\begin{tabular}{llll}
\hline$\chi_{S C}^{2}(1)$ & $\chi_{S C}^{2}(4)$ & Nor & Het \\
$0.32(0.26)$ & $0.62(0.65)$ & $3.53(0.17)$ & $1.65(0.13)$ \\
\hline
\end{tabular}

Tanı koyma sınamaları açısından $\chi_{S C}^{2}(1)$ ve $\chi_{S C}^{2}(4)$ ardışı bağımlılık (serial correlation) olmaması sıfır varsayımı altında birinci ve dördüncü dereceden Breusch-Godfrey hata terimleri Lagrange çarpanı testi $F$ - istatistiklerini, Nor hata terimlerinin normal dağılımı sıfır varsayımı altında Jarque-Bera normallik istatistiğini ve Het sabit varyanslılık sıfır varsayımı altında Breusch-Pagan-Godfrey değişen varyans testi $F$-istatistikleridir. İlgili olasılık değerleri parantez içerisindedir.

Tablo 3'ün incelenmesi $A R D L(3,1,3,0,0)$ modeli açısından herhangi bir tanı koyma sorunu ortaya koymamakta ve elde edilen hata terimlerinin beyaz gürültü hata terimi olma özelliğine sahip olduğunu göstermektedir. $A R D L$ modeline ait kısa dönem hata düzeltme modeli istatistiksel olarak anlamlı bulunan değişken katsayılarıyla birlikte Tablo 4 içerisinde sunulmaktadır. Tablo 4 göstermektedir ki uzun dönem durağan denge ilişkisinden sapmaların \%33'ü bir dönem içerisinde ortadan kalkmaktadır. Yani, tahmin edilen model doğrultusunda yaklaşık üç gözlem dönemi içerisinde SPMM döviz kuru belirlenme modeli denge koşullarının yeniden sağlandığ 1 anlaşılmaktadır. Hata düzeltme modeli içerisinde anlamlı bulunan farkı 
alınmış göreceli para arzı ve göreceli reel gelir düzeyi değişkenleri uzun dönem ARDL modelinde sahip oldukları özellikleri devam ettirmektedir.

Tablo 4: $\operatorname{ARDL}(3,1,3,0,0)$ Modeline Ait Koşullu Hata Düzeltme Regresyonu

\begin{tabular}{|c|c|c|c|c|}
\hline \multicolumn{5}{|c|}{ Bağımlı değişken : $d(e r)$} \\
\hline Değişken & Katsayı & Std.Hata & $t-i s t$ & olas. \\
\hline$d(e r)_{t-1}$ & 0.24 & 0.10 & 2.42 & 0.02 \\
\hline$d(e r)_{t-2}$ & 0.24 & 0.11 & 2.15 & 0.04 \\
\hline$d(\text { money })_{t}$ & 1.91 & 0.27 & 6.97 & 0.00 \\
\hline$d(\text { income })_{t}$ & -0.55 & 0.32 & -1.71 & 0.09 \\
\hline$d(\text { income })_{t-2}$ & -1.03 & 0.28 & -3.68 & 0.00 \\
\hline$E C_{t-1}$ & -0.33 & 0.05 & -6.09 & 0.00 \\
\hline C & 0.24 & 0.12 & 1.99 & 0.05 \\
\hline$R^{2}=0.65$ & $\operatorname{Adj} . R^{2}=0.60$ & \multicolumn{3}{|c|}{ Durbin - Watson stat $=2.17$} \\
\hline
\end{tabular}

\section{SONUÇ}

Çalışmamızda döviz kuru belirlenme mekanizmasının Türkiye ekonomisi koşullarında araştırılması amaçlanmıştır. $\mathrm{Bu}$ amaçla kuramsal temelli olarak oluşturduğumuz bir katı fiyat döviz kuru belirlenme modeli çağdaş zaman serisi ekonometrisindeki gelişmeler 1şığında tahmin edilmiştir. Gerçekleştirilen kuramsal temelli modelleme ve çağdaş tahmin yöntemleri kullanılarak bu modelin geçerliliğinin araştırılması çalışmanın iktisat yazınına başlıca bir katkısı durumundadır. TL / ABD doları parasal döviz kurunu dikkate alan tahmin bulgularımız döviz kurunun kuramsal temellere uygun bir şekilde çok değişkenli eşbütünleşik bir yapıda belirlendiğini göstermiştir. Parasal döviz kuru göreceli para arzıyla pozitif ve göreceli reel gelir düzeyiyle negatif ve istatistiksel olarak anlamlı bir ilişki içerisinde bulunmuştur. Diğer yandan, göreceli faiz oranı negatif ve göreceli enflasyon oranı pozitif bir şekilde uzun dönem durağan denge koşulları altında parasal döviz kurunu etkilemektedir. Dolayısıyla, pozitif bir göreceli enflasyon farklılığının gözlenmesi ulusal paranın ABD doları karşısında değer kaybetmesine neden olacaktır.

Elde edilen bu bulgular parasal döviz kurunun döviz piyasası denge koşulları dikkate alındığında uzun dönemde bir politika aracı olarak kullanılmaması gerektiğini ifade etmektedir. Bir başka deyişle, parasal döviz kurunun politika yapıcılar tarafından kendi beklentileri doğrultusunda bir araç olarak kullanılmaya çalışılması uzun dönemde kurun oluşumu kuramsal beklentiler doğrultusunda gerçekleşeceği için arzulanan politika sonuçlarının ortaya çıkmamasına neden olabilecektir.

Kendi çalışmamızda gerçekleştirdiğimiz denemenin örneklem dönemindeki değişikliklere karşı duyarlı olup olmadığı ilerleyen çalışmalarla mutlaka sınamaya tabi tutulmalıdır. $\mathrm{Bu}$ anlamda gerek satın alma gücü paritesinin gerekse de korunmamış faiz paritesinin ekonomideki ayrı ayrı geçerliliğini sınayacak çalışmalar kendi çalışmamız açısından 
tamamlayıcı olacaktır. Aynı zamanda döviz arz ve talep koşulları üzerinde önemli bir belirleyici olduğu varsayılabilecek sermaye akımlarının ya da gelişmekte olan bir ülke açısından çok daha ön planda dikkate alınabilecek portföy hareketlerindeki dalgalanmaların belirleyicilerinin ve bunların döviz kurlarıyla etkileşimini gösterebilecek denemelerin gelecek çalışmalar şeklinde ortaya konulması gerekliliği düşünülmektedir.

\section{KAYNAKÇA}

Abhyankar, A., Sarno, L. \& Valente, G. (2005). Exchange rates and fundamentals: evidence on the economic value of predictability. Journal of International Economics, 66, 325-348.

Afat, D., Gómez-Puig, M. \& Sosvilla-Rivero, S. (2015). The failure of the monetary model of exchange rate determination. Applied Economics, 47(43), 4607-4629.

Bahmani-Oskooee, M. \& Kara, O. (2000). Exchange rate overshooting in Turkey. Economics Letters, 68, 89- 93.

Chin, L., Azali, M. \& Matthews, K.G. (2007). The monetary approach to echange rate determination for Malaysia. Applied Financial Economics Letters, 3(2), 91-94.

Civcir, İ. (2004). The long-run validity of the monetary exchange rate model for a high inflation countryand misalignment: The case of Turkey. Emerging Markets Finance and Trade, 40(4), 84-100.

Engle, R.F. \& Granger, C.W.J. (1987). Co-integration and error correction: representation, estimation, and testing. Econometrica, 55, 251-276.

https://stats.oecd.org/, erişim tarihi: 06.12.2018.

https://www.sbb.gov.tr/, erişim tarihi: 06.12.2018

Johansen, S. (1995). Likelihood-based inference in cointegrated vector autoregressive models. Oxford: Oxford University Press.

Karfakis, C. (2006). Is there an empirical link between the dollar price of the euro and the monetary fundamentals?. Applied Financial Economics, 16, 973-980.

Lee, J. \& Strazicich, M.C. (2003). Minimum lagrange multiplier unit root test with two structural breaks. The Review of Economics and Statistics, 85(4), 1082-089.

Mark, N.C. \& Sul, D. (2001). Nominal exchange rates and monetary fundamentals evidence from a small post-Bretton woods panel. Journal of International Economics, 53, 29-52.

McNown, R. \& Wallace, M.S. (1994). Cointegration tests of the monetary exchange rate model for three highinflation economies. Journal of Money, Credit and Banking, 26(3), 396-411.

Meese, R. A. \& Rogoff, K. (1983). Empirical exchange rate models of the seventies: Do they fit out of sample?. Journal of International Economics, 14(1-2), 3-24.

Neely, C.J. \& Sarno, L. (2002). How well do monetary fundamentals forecast exchange rates?. FRB of St. Louis Review, September/October, 51-74.

Ozdemir, Z.A. (2004). Mean reversion in real exchange rate: empirical evidence from Turkey, 1980-1999. METU Studies in Development, 31, 243-265.

Pesaran, M.H., Shin, Y. \& Smith, R.J. (2001). Bounds testing approaches to the analysis of level relationships. Journal of Applied Econometrics, 16, 289-326.

Shylajan, C.S., Sereejesh, S. \& Suresh, K.G. (2011). Rupee-dollar exchange rate and macroeconomic fundamentals: An empirical analysis using flexible-price monetary model, Journal of International Business and Economy, 12(2), $89-105$.

Uz, İ. and Ketenci, N. (2010). Exchange rate determination: Monetary approach in the new EU members and Turkey. Applied Economics Letters, 17(10), 963-967. 


\section{Extended Summary}

\section{Exchange Rate Determination Model of TL / US Dollar: ARDL Bounds Testing Application}

This paper aims to examine the exchange rate determination model in a theoretical base by also applying to some empirical methodologies. For this purpose, TL / US dollar exchange rate is chosen as a research subject for the sample period 2005Q4 - 2018Q3 using quarterly frequency data. The reason to choose the initial period of the study is that from this date on, the Central Bank of the Republic of Turkey starts to calculate the money supplies as the sum of domestic currency-based deposits and foreign currency-based deposits in terms of domestic currency in the banking system. This study tries to make a contribution to the economics literature in terms of giving some estimation results of the theoretical background by utilizing contemporaneous econometric tests.

In the paper, the author first constructs a theoretical model by following the current literature, and then give some extensions derived from the assumptions considered. For this purpose, the flexible price monetary model and the sticky price monetary model of exchange rate determination has been taken into consideration so that the relationships between ex-ante assumed variables is set for testing purposes.

In this line of thought, the author aims to explain whether the behavior of exchange rate suits the theoretical fundamentals well for the Turkish case in a way leading to a policy inference. Such a result will also point out how suitable the use of exchange rate as a policy tool in stabilization programs.

The flexible price monetary model is introduced to the modeling phase by following the literature, which is based on the assumptions that relate price level and exchange rate changes to money supply changes in a methodology in the light of well-known quantity theory of money in economics. And then, the model takes into account the validity of purchasing power parity and integrates it into base model in the paper. Further, the model is extended by considering a price stickiness phenomenon settled in the economy to see the changes in expectations, so, the impact of the difference between price stickiness and the fully flexible prices in line of purchasing power parity ban be brought out.

The data used for empirical purposes in the paper has been collected from different sources. The monetary aggregate in the estimation process is the broadly defined M3 money supply for the Turkish and the US economies. This aggregate represents the sum of the amount of money in circulation, demand deposits in the banking system, time deposits in the banking system, repurchase agreements, money market funds and the total value of securities. For both the Turkish and US data have been compiled from the electronic data delivery system of Organization for Economic Cooperation and Development (https://stats.oecd.org/). For the monetary aggregates, an index with the base year 2010 has been considered. For the real income variable, again, the above-stated OECD resource has been used, and for this purpose, the gross domestic product data based on the chained volume indices for the Turkish and the US economies with the base years 2009 and 2012, respectively, have been taken into the estimation process. The inflation data represent the quarterly change in the consumer price indices using the base year 2015 for both economies, and the data for this variable has also been obtained from the OECD electronic data delivery system. Interest rate variable for Turkey is the term average of Treasury monthly borrowing compound interest rate, while three-month Treasury bond interest rate has been considered for the US economy. The interest rate data for Turkey have been collected from the electronic data delivery system of the Strategy and Budgetary Office of the President of the Republic of Turkey (https://www.sbb.gov.tr/), and the relevant interest data for the US economy is based on the OECD source above. For the nominal exchange rate, relative 
money supply and the relative income levels used in the empirical modelling, the natural logarithmic transformation has been applied to the data, while no such transformation has been assumed for the relative interest rate and relative inflation rate data.

For the estimation methodology used in the paper, the contemporaneous autoregressive distributed lag cointegration technique has been used due to the different integration order frameworks of the variables. This estimation has been implemented for different deterministic component assumptions in the empirical model constructed. Among the too many estimated models, the most appropriate model in a statistical and econometrical sense has been determined as the core model upon which both economic and statistical inferences can be made. The results indicate that nominal exchange rate is cointegrated with the fundamentals suggested by economics theory. There exists a positive relationship between nominal exchange rate and relative money supply and that an increase in the relative income would lead to an appreciation of the domestic currency against the US dollar. Besides, as a priori hypothesized, relative interest variable has a negative relationship and relative inflation differential has a positive relationship with the nominal exchange rate.

The findings obtained imply that under the exchange rate market equilibrium conditions which can be estimated in this study, nominal exchange rate should not be used as a policy tool. In other words, since the exchange rate determination occurs in line with theoretical expectations in the long run, the use of nominal exchange rate as a policy tool by the policy makers as to their own expectations can be resulted in undesirable policy outcomes in the economy. 
Optimum Journal of Economics and Management Sciences, Vo1. 7, No. 1- http://dergipark.gov.trloptimum Korap - Exchange Rate Determination Model of TL/US Dollar: ARDL Bounds Testing Application 